\title{
Atividade virtual no Facebook: comparando prefeituras gaúchas a partir de fatores demográficos, financeiros e políticos
}

\section{Virtual activity on Facebook: comparing municipalities in Rio Grande do Sul based on demographic, financial and political factors}

\author{
Monize Sâmara Visentini Doutora em Administração. Universidade Federal do Rio Grande do Sul (UFRGS) - Brasil. \\ monize.visentini@uffs.edu.br \\ Darlan Nei Writzl Graduando em Administração. Universidade Federal da Fronteira Sul (UFFS) - Brasil. darlan.writzl@outlook.com \\ Liara Laís Scheid Mestranda em Desenvolvimento e Políticas Públicas. Universidade Federal da Fronteira Sul (UFFS) - Brasil. \\ liarascheid@yahoo.com.br \\ Ari Söthe Doutor em Desenvolvimento Regional pela Fundação Universidade Regional de Blumenau (FURB) - Brasil. \\ ari.sothe@uffs.edu.br.
}

\section{RESUMO}

A sociedade vem exigindo das organizações públicas maior participação na gestão e monitoramento mais estrito da qualidade dos serviços, fazendo necessárias novas formas de aproximação dos governos com a sociedade, sendo as redes sociais um modo de comunicação entre esses atores. Assim, este estudo teve como objetivo comparar a atividade virtual média dos municípios gaúchos no Facebook considerando fatores demográficos, financeiros e políticos. Para isso, foram investigados 60 municípios do Rio Grande do Sul. A análise dos dados se deu por meio de estatística descritiva, teste Kolmogorov-Smirnov, teste t para amostras independentes e teste de Mann-Whitney. Os principais resultados apontam que, para os municípios gaúchos, a atividade virtual no Facebook, em média, é diferente conforme o número de fãs da página, o tamanho da população, a quantidade de idosos, a quantidade de pessoas com ensino superior, a capacidade econômica e a participação eleitoral dos municípios $(\mathrm{p}<0,05)$. Em média, a atividade virtual é igual independente da renda dos trabalhadores, da competitividade política, da condição de reeleição, do perfil do gestor municipal, do índice de transparência e do interesse do cidadão dos municípios ( $p>0,05)$. Os gestores municipais podem utilizar esses resultados para desenvolver novas práticas de publicações em suas redes sociais, capazes de divulgar atividades que abrangem o serviço público de uma maneira mais dinâmica e atrativa.

Palavras-chave: Publicações. Redes Sociais Virtuais. Indicadores.

\begin{abstract}
Society has been demanding greater participation of public organizations in the management and stricter monitoring of the quality of services, creating the need for new ways of bringing governments closer to society, and with social networks being a means of communication between these actors. So this study aimed to compare the average virtual activity of Rio Grande do Sul municipalities on Facebook considering demographic, financial and political factors. For this purpose, 60 municipalities in the Rio Grande do Sul were investigated. Data analysis was performed using descriptive statistics, Kolmogorov-Smirnov test, t-test for independent samples and Mann-Whitney test. The main results indicate that for the municipalities of Rio Grande do Sul, the virtual activity on Facebook, on average, is different according to the number of page fans, the population size, the number of elderly people, the number of people with higher education, the economic capacity and electoral participation of municipalities $(p<0.05)$. On average, virtual activity is the same regardless of workers' income, political competitiveness, reelection status, the profile of the municipal manager, the transparency index and the interest of citizens in the municipalities ( $p>0.05$ ). Municipal managers can use these results to develop new publishing practices on their social networks, capable of promoting activities that cover the public service more dynamically and attractively.
\end{abstract}

Keywords: Publications. Virtual Social Networks. Indicators. 


\section{INTRODUÇÃO}

A sociedade vem exigindo das organizações públicas, em especial dos governos, aumento da transparência na aplicação dos recursos, maior participação na gestão, monitoramento mais estrito da qualidade dos serviços e aumento da responsabilidade dos gestores públicos. Com isso, se fazem necessárias novas formas de gestão e de aproximação dos governos com a sociedade (ALBANO; ARAUJO; REINHARD, 2017), sendo a criação de perfis nas redes sociais um modo de comunicação entre esses atores (REIS, 2015). López Alonso e Moreno López (2019) destacam que a plataforma mais utilizada pelos municípios rurais da Espanha que possuem redes sociais institucionais é o Facebook, com 93,04\% de inserção. Em Buenos Aires também há uma preferência da administração pública pelo Facebook, seguido do Twitter e YouTube (URE, 2016).

No Brasil, $73 \%$ das prefeituras realizam atividades virtuais em redes sociais on-line de relacionamento como Facebook, Yahoo Profile e Google+, em seguida estão as redes de vídeos, como YouTube e Vimeo (19\%), em um patamar inferior estão as de imagem e vídeos, como Instagram, Flickr, Periscope ou Snapchat (17\%) e de mensagem, como WhatsApp e Telegram (17\%) (CETIC, 2017). Nota-se que as vantagens de se ter uma atividade virtual ativa, em especial nas redes sociais, não passaram despercebidas pela administração pública, que descobriram uma nova maneira de comunicação com os cidadãos (RODRÍGUEZ-DOMÍNGUEZ; SÁNCHEZ; ÁLVAREZ, 2011).

A definição de atividade virtual aqui adotada é a mesma que foi proposta por Lameiras, Silva e Tavares (2018), que consiste na soma de todas as postagens realizadas na página de cada município. Estudos anteriores (GUILLAMÓN et al., 2016; LAMEIRAS, SILVA; TAVARES, 2018; FABER; BUDDING; GRADUS, 2019) indicam que alguns fatores demográficos, econômicos e políticos dos municípios podem estar relacionados com a atividade virtual dos governos nas redes sociais, sendo esses os fatores investigados neste estudo.

Através da pesquisa busca-se responder ao seguinte questionamento: Qual a atividade virtual média dos municípios gaúchos no Facebook considerando fatores demográficos, financeiros e políticos? A partir do problema exposto, o presente artigo tem como objetivo comparar a atividade virtual média dos municípios gaúchos no Facebook considerando fatores demográficos, financeiros e políticos.

Este estudo buscou investigar municípios do Rio Grande do Sul (RS). Um indicador relevante para esta escolha foi que o estado possui nota 10 na Escala Brasil Transparente (EBT), em escala de 0 a 10 (Controladoria Geral da União [CGU], 2017), sendo que a transparência dos municípios será uma das variáveis analisadas. Também vale enfatizar que estudos anteriores exploraram apenas regiões do Rio Grande do Sul ou municípios isolados do estado (PIRES, 2013; HOSSER et al., 2015; VISENTINI; SANTOS, 2019), mas poucos estudaram de forma probabilística um cenário completo, o que diferencia esta investigação. Entende-se que a nota da transparência pública é um bom indicativo da busca pela democratização da informação junto aos cidadãos, podendo essa ser realizada por canais virtuais, como o site institucional ou as mídias sociais.

A pesquisa se justifica, pois, no cenário político atual, se faz necessário entender o papel das mídias sociais como canais de interação entre governo e cidadãos (MERGEL, 2013). Apesar da crescente atenção à análise de conteúdo gerado pelos usuários das mídias sociais, a literatura indica que faltam métricas adequadas que identifiquem os impactos das ações virtuais dos governos (MERGEL, 2013; HOFMANN et al., 2013).

Considera-se, também, que o aumento da interação dos governos por meio de mídias sociais melhora a percepção dos cidadãos sobre a transparência, pois elas permitem que os cidadãos ganhem acesso mais fácil a informações atualizadas do governo (SONG; LEE, 2016). Usando plataformas de mídia social, o governo pode trazer agenda e atividades do setor mais próximas dos cidadãos, promover novas formas de prestação de contas e melhorar a transparência no setor público, vista como uma maneira de melhorar a confiança dos cidadãos nos governos (BONSÓN et al., 2012; NICA et al., 2014).

Diante disso, percebe-se o diferencial desta investigação, que abrange municípios gaúchos selecionados de modo probabilístico, e possibilita uma compreensão inicial da atividade virtual dessas prefeituras. Assim, espera-se que a investigação, contribua para verificar a efetividade desta ferramenta de comunicação entre governo e cidadãos, assim como a participação cidadã nestes ambientes. Santana e Souza 
(2017) destacam que, na esfera pública, o monitoramento das redes sociais pode contribuir na elaboração de políticas públicas, ao possibilitar uma avaliação rápida e de baixo custo das opiniões, atitudes e sentimentos das pessoas e dos líderes de opinião digitais.

\section{ATIVIDADE VIRTUAL NO FACEBOOK}

Dentre as redes sociais mais destacadas está o Facebook (AMARAL, 2016), uma plataforma utilizada para fins sociais, culturais ou até mesmo políticos e que traz novas possibilidades de acesso, produção, divulgação e troca de informações (ARAUJO, 2012). O Facebook foi criado em 2004 por Mark Zuckerberg e atualmente é a maior rede social do mundo com 2,3 bilhões de usuários ativos mensais globais no quarto bimestre de 2018 (STATISTA, 2019a). No Brasil, o número de usuários aumentou de 71,9 milhões em 2017 para 75,6 milhões em 2018 (STATISTA, 2019b).

O Facebook disponibiliza várias ferramentas de interação, sendo que neste estudo salienta-se a versatilidade das páginas. De acordo com Kleina (2014) as páginas (fanpages, em inglês) são parecidas com os perfis tradicionais, mas em vez de adicionar amigos recebem curtidas. É uma das ferramentas mais democráticas oferecidas pelo Facebook e representam temáticas como pessoas, lugares, marcas ou instituições.

A atividade virtual no Facebook pode ser medida pelo tipo de publicação. Nesse estudo, serão analisados seis tipos de publicações, que estão especificadas no Quadro 1.

Quadro 1 - Tipos de publicação que medem a atividade virtual no Facebook

\begin{tabular}{|c|c|c|}
\hline Publicação & Descrição & Autores \\
\hline Texto & $\begin{array}{l}\text { Textos curtos e objetivos (até } 120 \text { caracteres) para evitar que o } \\
\text { conteúdo seja encurtado pela própria plataforma. } \\
\text { Textos curtos tendem a receber mais atenção dos usuários. } \\
\text { Precisa ser coloquial, próximo da linguagem que o cidadão utiliza } \\
\text { em seu dia a dia. }\end{array}$ & Brasil (2014) \\
\hline Imagem & $\begin{array}{l}\text { Transmitem informações sobre diferentes contextos, ligando o } \\
\text { sensível e o racional. }\end{array}$ & $\begin{array}{l}\text { Rosa, Cruz e } \\
\text { Emerim (2018) }\end{array}$ \\
\hline Vídeo & $\begin{array}{l}\text { Todos os vídeos devem ter título e legenda descrevendo-os e } \\
\text { apontando nomes de personalidades envolvidas, local e data (dia, } \\
\text { mês, ano) para contextualizar a informação para o cidadão. }\end{array}$ & Brasil (2014) \\
\hline Link & $\begin{array}{l}\text { Direcionam os internautas a páginas ou sítios on-line que contém } \\
\text { mais informações sobre o assunto contido no post. }\end{array}$ & $\begin{array}{c}\text { Farranha e Santos } \\
\text { (2015) }\end{array}$ \\
\hline Gif & $\begin{array}{l}\text { Consistem em animações breves, silenciosas, de baixa resolução e } \\
\text { que se repetem em um loop infinito. São aplicados para expressar } \\
\text { ideias, reações ou emoções, e até mesmo para substituir o texto } \\
\text { escrito. }\end{array}$ & Lupinacci (2016) \\
\hline Status & $\begin{array}{l}\text { Permite que os usuários compartilhem seus pensamentos, } \\
\text { sentimentos e atividades com amigos, que têm as opções de curtir } \\
\text { e comentar em troca. }\end{array}$ & $\begin{array}{l}\text { Marshall, } \\
\text { Lefringhausen e } \\
\text { Ferenczi (2015) }\end{array}$ \\
\hline
\end{tabular}

Fonte: Elaborado pelos autores (2020) com base na literatura.

Com relação aos tipos de postagens do Facebook feitas com mais frequência pelos municípios estão as que incluem algum tipo de conteúdo adicional (por exemplo, imagens, vídeos ou links) (LAMEIRAS; SILVA; TAVARES, 2018), sendo que os links ganham mais destaque por estarem presentes em um número maior de publicações (FABER; BUDDING; GRADUS, 2019). Farranha e Santos (2015) apontam imagens com frases diretas ou esquemas explicativos e os links como recursos largamente utilizados pela página da Controladoria Geral da União (CGU). Os links instigam os usuários a pesquisarem e se aprofundar mais sobre as questões apresentadas nas postagens. 


\section{FATORES ASSOCIADOS À ATIVIDADE VIRTUAL NA GESTÃO PÚBLICA MUNICIPAL}

A partir da literatura (GUILLAMÓN et al., 2016; LAMEIRAS; SILVA; TAVARES, 2018) foram identificados três fatores que podem influenciar a atividade virtual dos municípios nas redes sociais: fatores demográficos, fatores econômicos e fatores políticos.

Com relação aos fatores demográficos, segundo Guillamón et al. (2016) e Lameiras, Silva e Tavares (2018), existem três características da população municipal que podem explicar o nível de atividade virtual dos municípios nas mídias sociais, que são o tamanho da população, a idade da população e o nível de escolaridade. No que tange aos fatores econômicos, destaca-se a capacidade econômica dos municípios, pois mesmo que criar e regulamentar uma conta em uma mídia social seja relativamente simples, o monitoramento e a manutenção eficazes dessa conta podem custar caro em termos de tempo e recursos, e também a renda per capita, visto que o status econômico da população pode influenciar no acesso e uso de mídias sociais por parte dos cidadãos (GUILLAMÓN et al., 2016; LAMEIRAS; SILVA; TAVARES, 2018). Por fim, os fatores políticos englobam as características do gestor municipal, dado que os municípios são gerenciados por pessoas (políticos), sua personalidade pode influenciar o estilo administrativo do município. Assim, os políticos podem ou não promover o uso de mídia social. Além do compromisso dos municípios em transparência, o grau de competição política, o interesse dos cidadãos nas mídias sociais dos governos locais, a participação dos cidadãos nas eleições para prefeito e reeleições (LAMEIRAS; SILVA; TAVARES, 2018).

Faber, Budding e Gradus (2019) desenvolveram um estudo com o objetivo de avaliar o uso de mídias sociais pelos governos locais holandeses. Foram analisados todos os 380 municípios do país e como as mídias sociais são usadas por eles. Os autores notaram, com relação a fatores demográficos, que entre os quatro maiores municípios do país em 2018 (Amsterdã, Roterdã, Haia e Utrecht) nenhum foi consistentemente o mais ativo em todas as plataformas pesquisadas (Twitter, Facebook. Linkedln, YouTube e Instagram). Já resultados obtidos por Guillamón et al. (2016) demonstraram, através de uma pesquisa com 217 municípios italianos e espanhóis que usaram o Facebook em 2014, que os governos locais usam mais aplicativos de mídia social para divulgar informações quando o tamanho da população é maior. Resultados obtidos por Lameiras, Silva e Tavares (2018) demonstraram que a proporção de fãs do Facebook em relação à população foi, em geral, mais alta em municípios com população menor.

De acordo com Santos e Santos (2014), a camada populacional que mais faz uso de redes sociais é considerada jovem (entre 18 e 25 anos de idade) e o grau de escolaridade dos usuários é elevado. Geralmente, o uso de mídias sociais é caracterizado pela presença de pessoas com formação superior (FABER; BUDDING; GRADUS, 2019). Uma pesquisa realizada no Twitter por Marques, Aquino e Miola (2014), com o objetivo de investigar que fatores levam parlamentares a investir na rede social como parte de sua estratégia de comunicação política, demonstrou que quanto maior o número de eleitores com nível de escolaridade superior, maior a utilização do Twitter pelos deputados.

Santos (2016) realizou um estudo a partir da página do "Senado Federal" brasileiro no Facebook, indicando que $o$ alcance das publicações entre as pessoas com mais de 65 anos é pequeno. No entanto Wasserman et al. (2012) apontam o Facebook como a rede social mais usada pelos idosos, por se tratar de um ambiente acessível para esses usuários, levando a crer que, em municípios com um maior contingente de população em idade mais avançada, haja uma atuação dinâmica deles nesta rede social.

O estudo de Ribeiro e Zuccolotto $(2012$, p. 13) constatou, a respeito de fatores econômicos, que "municípios com maior arrecadação relativa (receita orçamentária per capita) tendem a divulgar mais informações em meio eletrônico de acesso público devido à disponibilidade de recurso para investimento na gestão da informação".

No que concerne à renda dos cidadãos, a literatura não tem consenso sobre os reflexos desta variável. Alguns estudos apontam que os governos locais são mais propensos a oferecer serviços e divulgar informações através de sites e/ou mídias sociais nos municípios em que o nível de renda dos cidadãos é mais baixo (GUILLAMÓN et al., 2016). Esses autores destacam que cidadãos com renda mais baixa tendem a usar as mídias sociais por serem muito populares, baratas e fáceis. Nesse sentido, cidadãos de baixa renda podem exigir mais informações por meio desses meios de comunicação e, por sua vez, os governos locais as podem estar 
aplicando para alcançar essa parcela da população. Entretanto, Duggan e Brenner (2013) apontam que o uso do Facebook parece ser mais comum entre pessoas com maior renda, sendo esta a perspectiva mais difundida na literatura. Acredita-se, assim, que a relação entre a variável renda da população e estímulo à atividade virtual no Facebook esteja diretamente relacionada ao país de origem da investigação, estimulando a verificação desta possível associação no Brasil.

Quanto aos fatores políticos, sobre as características dos prefeitos, a idade tem uma relação significativa com as atividades do município no Facebook, sendo que os municípios com prefeitos mais jovens são mais ativos nos meios de comunicação social (LAMEIRAS; SILVA; TAVARES, 2018). O sexo do gestor municipal também tem despontado em investigações como relevante à análise da atividade virtual, sendo que há a indicação de uma participação mais ativa nas redes sociais em governos chefiados por mulheres, pelos seus estilos de liderança mais democráticos e mais abertos (TAVARES; CRUZ, 2017). Quanto ao grau de instrução do gestor municipal, Dreher et al. (2009) destacam que a maior educação e a formação profissional dos políticos estão associadas à implementação de formas de gestão mais democráticas, sendo as redes sociais um exemplo dessa prática.

A respeito da competitividade política, quanto mais competitivas as eleições municipais, mais ativo 0 município estará no Facebook (LIMEIRA; SILVA; TAVARES, 2018). Effing, Hillegersberg e Huibers (2011) analisaram o impacto das mídias sociais nas eleições de 2010 e 2011 na Holanda e constataram que não desempenham um grande papel nas eleições municipais. Por outro lado, Lameiras, Silva e Tavares (2018) destacam que a participação dos eleitores deveria ser positivamente associada à atividade do município nas mídias sociais, por ser um indicador de envolvimento e interesse em questões políticas locais.

Finalmente, municípios com alto nível de uso do Facebook tendem a aumentar o grau de transparência, pois disponibilizam dados e informações sobre os serviços públicos que podem ser acessados facilmente pelos cidadãos (HARO-DE-ROSARIO; SÁEZ-MARTíN; CABA-PÉREZ, 2018; GUILLAMÓN et al., 2016).

Nica et al. (2014) enfatizam a importância do uso das mídias sociais no setor público, pois promovem a participação cidadã e são vistas como um instrumento para aumentar as práticas de boa governança, principalmente em matérias de transparência, ampliando a prestação de contas e facilitando a comunicação e interação entre as partes interessadas. Para Luciano, Wiedenhöft e Santos (2018) a falta de envolvimento do cidadão em questões governamentais e a falta de iniciativas do próprio governo no meio digital são consideradas barreiras que afetam o grau de engajamento e participação do público. No entanto, as mídias sociais permitem que as pessoas se comuniquem com as organizações públicas locais de forma mais ampla e rápida, podendo fazer solicitações ou reclamações ao município que, por sua vez, percebe os problemas mais facilmente e pode atuar no planejamento e formulação de políticas para solucioná-los (ROENGTAM, 2017).

\section{METODOLOGIA}

A pesquisa desenvolvida, no que tange aos objetivos, trata-se de uma pesquisa descritiva (GIL, 2008), de abordagem quantitativa, a partir da coleta de dados secundários e dados primários. Os dados secundários foram obtidos dos sites da Secretaria do Tesouro Nacional (Sinconfi), do Instituto Brasileiro de Geografia e Estatística (IBGE), do Tribunal Superior Eleitoral (TSE) e do Ministério Público Federal (MPF), conforme as bases de dados destacadas no Quadro 2. Já os dados primários referem-se aos coletados nas páginas das prefeituras gaúchas no Facebook.

A população de interesse do estudo são os 497 municípios do estado do Rio Grande do Sul. Realizouse um cálculo amostral com intervalo de confiança de $90 \%$ e um erro amostral de $10 \%$, para uma distribuição da população heterogênea (50/50). Assim a amostra do estudo contemplará 60 municípios gaúchos selecionados por meio da amostragem aleatória simples.

Após a identificação dos municípios foi realizada uma busca no Facebook para verificar se eles possuíam conta na rede social Facebook utilizando os termos "Prefeitura Municipal", "Prefeitura" e/ou "Governo Municipal" seguido do nome do município. Ao identificar a conta oficial do município, foram avaliados outros critérios para a aprovação do município como elemento da amostra do estudo. Foram 
selecionados somente os municípios que possuíam páginas (fanpage), excluindo e substituindo aqueles que apresentavam contas no Facebook como perfis. Outro critério de análise foi a data de criação da página, sendo que foram selecionados apenas municípios que possuíam contas criadas anteriormente a 2019, já que a coleta de dados do Facebook compreende o primeiro semestre desse ano.

Acerca da atividade virtual, para compor a amostra do estudo, os municípios deveriam possuir, no mínimo, uma publicação mensal no decorrer dos seis meses de análise. E por fim, o último critério de análise para selecionar o município para a amostra da pesquisa, foi verificar o patrocínio nas publicações vinculadas a página do município. Sendo que somente foi considerado como amostra, os municípios que não utilizavam esta prática, ou seja, municípios que utilizam apenas o alcance orgânico ${ }^{1}$ para atingir seus usuários.

Em relação à coleta de dados, ela foi dividida em dois momentos. Primeiramente, foi realizada a coleta das atividades virtuais realizadas pelos municípios gaúchos no Facebook. As informações foram obtidas nas contas ativas do Facebook dos municípios, considerando as postagens realizadas no primeiro semestre de 2019 (de janeiro a junho). A coleta de dados referentes à atividade virtual do Facebook foi realizada de forma manual, na qual as postagens eram contadas e classificadas de acordo com o tipo (texto, imagem, vídeo, link, gife status).

O segundo momento da coleta dos dados constitui-se na coleta das variáveis explicativas (Quadro 2), a qual ocorreu através de diversos sites. A pesquisa inclui três variáveis dummy (reeleição, gênero e grau de instrução do gestor municipal), considerando-se, respectivamente, 1 à condição de reeleição do atual prefeito; 1 o sexo feminino; e 1 se o gestor possuir nível superior.

Quadro 2 - Variáveis Explicativas do estudo

\begin{tabular}{|c|c|c|c|c|}
\hline Fatores & Variável & Descrição & $\begin{array}{l}\text { Base para a coleta } \\
\text { dos dados e ano }\end{array}$ & Hipóteses \\
\hline \multirow{3}{*}{ 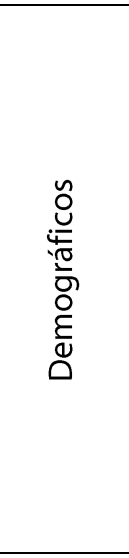 } & $\begin{array}{l}\text { Tamanho da } \\
\text { população }\end{array}$ & $\begin{array}{l}\text { Número de habitantes } \\
\text { de cada município. }\end{array}$ & $\begin{array}{l}\text { Instituto Brasileiro de } \\
\text { Geografia e Estatística } \\
\text { - IBGE (2016) }\end{array}$ & $\begin{array}{l}\text { H1: A atividade virtual no } \\
\text { Facebook é maior em } \\
\text { municípios com maior } \\
\text { porte populacional. }\end{array}$ \\
\hline & $\begin{array}{l}\text { Idade da } \\
\text { população }\end{array}$ & $\begin{array}{l}\text { Número de munícipes } \\
\text { com idade igual ou } \\
\text { superior a } 60 \text { anos. }\end{array}$ & $\begin{array}{l}\text { Tribunal Superior } \\
\text { Eleitoral - TSE (2016) }\end{array}$ & $\begin{array}{l}\text { H2: A atividade virtual no } \\
\text { Facebook é maior nos } \\
\text { municípios com maior } \\
\text { número de idosos. }\end{array}$ \\
\hline & $\begin{array}{l}\text { Escolaridade } \\
\text { da população }\end{array}$ & $\begin{array}{c}\text { Grau de instrução } \\
\text { correspondente ao } \\
\text { nível de escolaridade } \\
\text { da população } \\
\text { (superior completo). }\end{array}$ & TSE (2016) & $\begin{array}{l}\text { H3: A atividade virtual no } \\
\text { Facebook é maior nos } \\
\text { municípios com maior } \\
\text { número de pessoas com } \\
\text { ensino superior. }\end{array}$ \\
\hline \multirow{2}{*}{ 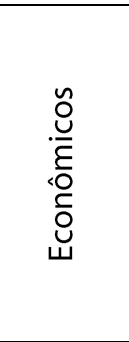 } & $\begin{array}{l}\text { Capacidade } \\
\text { econômica }\end{array}$ & Receita arrecadada & $\begin{array}{c}\text { Secretaria do Tesouro } \\
\text { Nacional (Sinconfi) } \\
(2018)\end{array}$ & $\begin{array}{l}\text { H4: A atividade virtual no } \\
\text { Facebook é maior em } \\
\text { municípios com maior } \\
\text { receita arrecadada. }\end{array}$ \\
\hline & $\begin{array}{l}\text { Renda per } \\
\text { capita }\end{array}$ & $\begin{array}{c}\text { Salário médio mensal } \\
\text { dos trabalhadores } \\
\text { formais }\end{array}$ & IBGE (2017) & $\begin{array}{l}\text { H5: A atividade virtual no } \\
\text { Facebook é maior em } \\
\text { municípios com maior } \\
\text { renda per capita. }\end{array}$ \\
\hline \multirow[t]{2}{*}{ 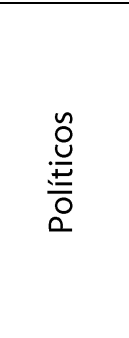 } & $\begin{array}{l}\text { Competitivi- } \\
\text { dade política }\end{array}$ & $\begin{array}{c}\text { Diferença entre o } \\
\text { percentual de votos } \\
\text { do primeiro e segundo } \\
\text { colocados da última } \\
\text { eleição }\end{array}$ & TSE (2016) & $\begin{array}{l}\text { H6: A atividade virtual no } \\
\text { Facebook é maior em } \\
\text { municípios com mais } \\
\text { competitividade política. }\end{array}$ \\
\hline & $\begin{array}{l}\text { Reeleição } \\
\text { (dummy) }\end{array}$ & $\begin{array}{c}\text { Condição de reeleição } \\
\text { do atual prefeito } \\
\text { municipal. }\end{array}$ & TSE (2016) & $\begin{array}{l}\text { H7: A atividade virtual no } \\
\text { Facebook é maior em }\end{array}$ \\
\hline
\end{tabular}

10 alcance orgânico se refere ao número de pessoas que se pode atingir de graça no Facebook com as publicações na página (FACEBOOK, 2017). 


\begin{tabular}{|c|c|c|c|}
\hline & & & $\begin{array}{l}\text { municípios em que houve } \\
\text { reeleição. }\end{array}$ \\
\hline $\begin{array}{l}\text { Participação } \\
\text { eleitoral }\end{array}$ & $\begin{array}{l}\text { Percentual de eleitores } \\
\text { do município que } \\
\text { participaram da última } \\
\text { eleição. }\end{array}$ & TSE (2016) & $\begin{array}{l}\text { H8: A atividade virtual no } \\
\text { Facebook é maior em } \\
\text { municípios com maior } \\
\text { participação eleitoral. }\end{array}$ \\
\hline $\begin{array}{l}\text { Sexo do ges- } \\
\text { tor municipal } \\
\quad(\text { dummy })\end{array}$ & $\begin{array}{c}\text { Sexo do líder do } \\
\text { executivo municipal. }\end{array}$ & TSE (2016) & $\begin{array}{l}\text { H9: A atividade virtual no } \\
\text { Facebook é maior em } \\
\text { municípios administrados } \\
\text { por mulheres. }\end{array}$ \\
\hline $\begin{array}{l}\text { Idade do } \\
\text { gestor } \\
\text { municipal }\end{array}$ & $\begin{array}{l}\text { Número de anos de } \\
\text { vida do gestor } \\
\text { municipal. }\end{array}$ & TSE (2016) & $\begin{array}{l}\text { H10: } \mathrm{A} \text { atividade virtual no } \\
\text { Facebook é maior em } \\
\text { municípios em que o gestor } \\
\text { municipal é mais novo. }\end{array}$ \\
\hline $\begin{array}{l}\text { Grau de ins- } \\
\text { trução do } \\
\text { gestor muni- } \\
\text { cipal (dummy) }\end{array}$ & $\begin{array}{l}\text { Grau de instrução } \\
\text { correspondente ao } \\
\text { nível de escolaridade } \\
\text { do gestor municipal. }\end{array}$ & TSE (2016) & $\begin{array}{l}\text { H11: A atividade virtual no } \\
\text { Facebook é maior em } \\
\text { municípios em que o } \\
\text { prefeito possui ensino } \\
\text { superior. }\end{array}$ \\
\hline Transparência & Nota da transparência. & $\begin{array}{l}\text { Ministério Público } \\
\text { Federal (2016) }\end{array}$ & $\begin{array}{l}\text { H12: A atividade virtual no } \\
\text { Facebook é maior em } \\
\text { municípios com maior } \\
\text { transparência. }\end{array}$ \\
\hline $\begin{array}{l}\text { Interesse dos } \\
\text { cidadãos }\end{array}$ & $\begin{array}{l}\text { Razão entre o número } \\
\text { de fãs do município na } \\
\text { página do Facebook } \\
\text { para o tamanho da } \\
\text { população do } \\
\text { município. }\end{array}$ & $\begin{array}{l}\text { Página de cada } \\
\text { município e IBGE } \\
\text { (2019) }\end{array}$ & $\begin{array}{l}\text { H13: A atividade virtual no } \\
\text { Facebook é maior em } \\
\text { municípios com maior } \\
\text { interesse dos cidadãos na } \\
\text { fanpage. }\end{array}$ \\
\hline
\end{tabular}

Fonte: Elaborado pelos autores, 2020.

O período de coleta de dados para o estudo foi de 22 de agosto à 29 de outubro de 2019. Os dados quantificados foram analisados através do software Statistical Package for the Social Sciences ${ }^{\mathrm{TM}}-$ SPSS 21.0 versão livre para testes e submetidos a análises estatísticas.

Para análise dos dados, primeiramente, foi aplicada uma análise estatística descritiva para a descrição da atividade virtual dos municípios gaúchos nas páginas e para a descrição das variáveis explicativas (fatores demográficos, econômicos e políticos). A normalidade das variáveis foi testada por meio do teste KolmogorovSmirnov. De acordo com Field (2009), o teste informa se os escores de uma amostra são normalmente distribuídos. Se o teste é significativo $(p<0,05)$, a distribuição em questão é não normal. Posteriormente foram realizados testes de hipóteses para os grupos das variáveis, considerando como variável dependente a atividade virtual. Os grupos foram definidos pela mediana da variável. Para as variáveis dummy (0 e 1) utilizouse os dois grupos previamente estabelecidos.

Os grupos das variáveis foram comparados através de teste t para amostras independentes e teste de Mann-Whitney. De acordo com Field (2009), o teste $t$ para amostras independentes é utilizado quando diferentes participantes foram indicados para duas condições experimentais existentes. $\mathrm{O}$ teste $\mathrm{t}$ independente é um teste paramétrico fundamentado na distribuição normal, ou seja, é considerado que os dados são de populações normalmente distribuídas. O teste t para amostras independentes foi testado ao nível de $5 \%$ de significância. Assume-se como hipótese nula que as médias entre dois grupos é igual e como hipótese experimental que as médias entre dois grupos diferem. Já o teste de Mann-Whitney é um teste não paramétrico (AGRESTI; FINLAY, 2012) que se apoia nos escores transformados em postos, deste modo, o grupo com maior número de postos baixos é aquele com a menor média. É utilizado quando se têm dados não normalmente distribuídos (FIELD, 2009). Os pesquisadores optaram por aplicar o teste $\mathrm{t}$ para amostras 
independentes e o teste de Mann-Whitney tanto para dados com distribuição normal como para dados com distribuição não normal, a fim de corroborar os resultados da investigação.

\section{ANÁLISE DOS RESULTADOS}

Essa seção descreve os principais resultados obtidos por meio da coleta de dados realizada para os municípios da amostra.

\subsection{Análise descritiva das variáveis estudadas}

Com relação às páginas dos municípios no Facebook constatou-se que a mais antiga foi criada em 01 de outubro de 2010 e refere-se ao município de Porto Alegre. A página mais nova é do município de Getúlio Vargas, criada em 16 de dezembro de 2018. A média de número de fãs das páginas dos municípios gaúchos estudados, no Facebook, é de 8.613,87, sendo que o município de Porto Alegre apresentou a maior quantidade de fãs (111.261) e o município de Coqueiros do Sul a menor quantidade de fãs (682).

Referente à atividade virtual, a média mensal de cada tipo de publicação postada na página do Facebook dos municípios gaúchos pode ser conferida no Gráfico 1.

\section{Gráfico 1 - Média Mensal dos tipos de publicação}

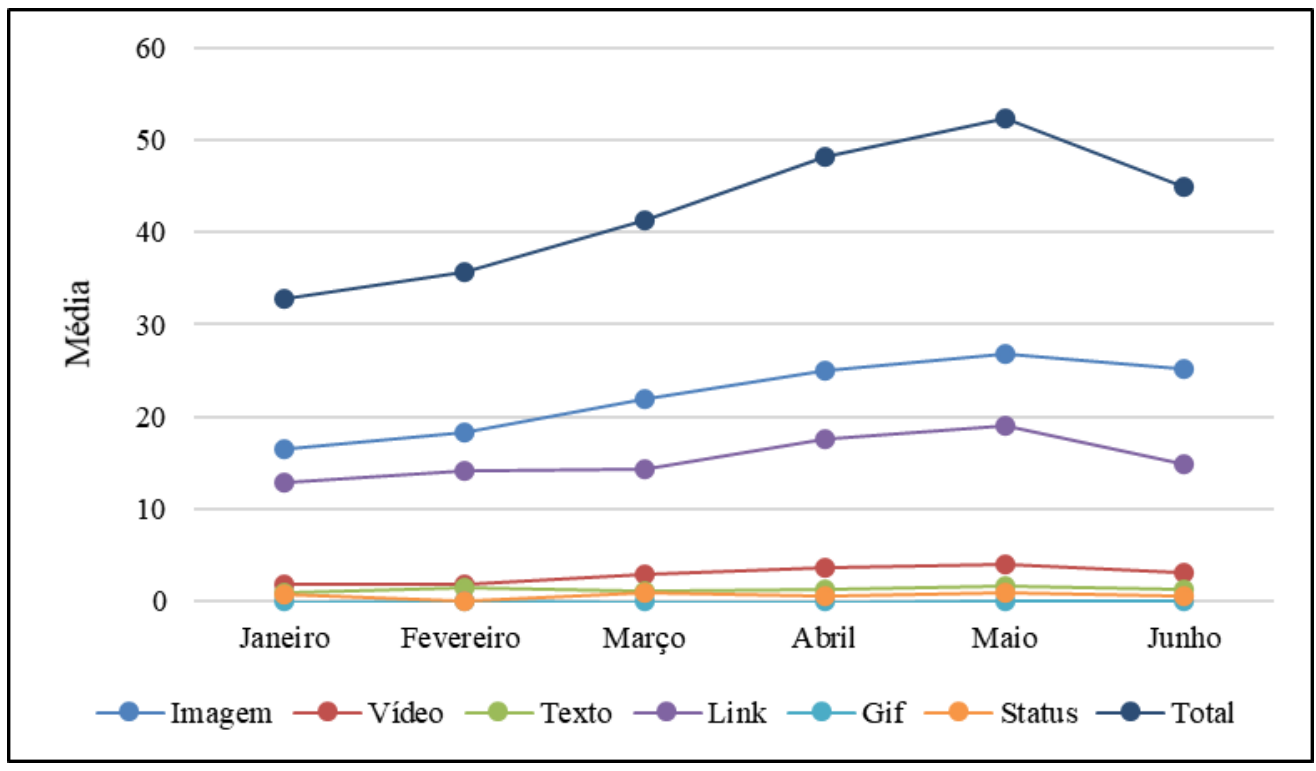

Fonte: Elaborado pelos autores (2020).

Por meio do Gráfico 1 pode-se observar que o mês com o maior número de publicações foi maio, com um média de 52,32 publicações, sendo que a maioria foram imagens $(26,87)$, seguidas de links $(19,03)$, vídeos $(3,93)$, textos $(1,63)$, status $(0,82)$ e gif $(0,03)$. As publicações ocorrem com menos frequência nos primeiros meses analisados, esse fator pode ser explicado pela razão de ser época de férias em que, geralmente, as prefeituras têm suas atividades reduzidas. Analisando o período completo de seis meses a média de publicações é de 255,42, representada por 133,93 imagens, 92,85 links, 17,30 vídeos, 7,68 textos, 3,57 status e 0,08 gif.

Os tipos de publicações mais realizados pelas prefeituras são imagens e links. Farranha e Santos (2015) observaram o mesmo ao analisar a página da CGU no Facebook, apontando as imagens que incluíam frases objetivas ou esquemas explicativos como recursos que ajudam o cidadão a obter informações em programas, fazer denúncias, realizar pedidos e acessar diversos outros serviços e os links instigam o usuário a aprofundar 
e pesquisar mais sobre as questões apresentadas, direcionando-os a páginas ou sites on-line que contém mais informações sobre o assunto contido no post.

Considerando-se a análise descritiva das demais variáveis do estudo, na Tabela 1 estão detalhados os valores mínimos e máximos de cada uma das variáveis quantitativas e suas respectivas médias.

No que concerne aos fatores demográficos percebe-se que a média do tamanho da população dos municípios gaúchos é de 45.941,05 habitantes, sendo que o município mais populoso é Porto Alegre, com 1.481.019 habitantes e o menos populoso é Lagoa dos Três Cantos com 1.649 habitantes. A média da população idosa, ou seja, com 60 anos ou mais é de 7.860,62 habitantes. Porto Alegre registrou o maior número de idosos (268.993) e São Vendelino o menor (332). Quanto à escolaridade da população, verificou-se uma média de $3.283,18$ pessoas que possuem ensino superior. O município com o maior número de habitantes com ensino superior é Porto Alegre (142.233) e o menor é Sede Nova (61).

Quanto aos fatores econômicos, notou-se que o município com a maior capacidade econômica é Porto Alegre com uma receita de R\$ 6.020.802.363,98 e o menor é Santa Tereza com R\$11.483.590,42 de receita arrecadada. A média desta variável para os municípios é de $\mathrm{R} \$ 177.414 .121,03$. Com relação a renda per capita, que diz respeito ao salário médio mensal dos trabalhadores formais, constatou-se que Triunfo apresentou o maior índice com 5,5 salários e Tabaí o menor com 1,7 salário.

Tabela 1 - Análise Descritiva das Variáveis Quantitativas

\begin{tabular}{clccc}
\hline Fatores & \multicolumn{1}{c}{ Variável } & Mínimo & Máximo & Média \\
\hline \multirow{2}{*}{ Demográficos } & Tamanho da população & 1.649 & 1.481 .019 & $45.941,05$ \\
& Idade da população & 332 & 268.993 & $7.860,62$ \\
& Escolaridade da população & 61 & 142.233 & $3.283,18$ \\
\hline \multirow{2}{*}{ Econômicos } & Capacidade econômica & $11.483 .590,42$ & $6.020 .802 .363,98$ & $177.414 .121,03$ \\
& Renda per capita & 1,7 & 5,5 & 2,34 \\
\hline \multirow{2}{*}{ Políticos } & Competitividade política & 0 & 43,12 & 12,72 \\
& Participação eleitoral & 57,62 & 95,21 & 83,40 \\
& Idade do gestor municipal & 25 & 75 & 51,72 \\
& Transparência & 1,4 & 10 & 7,41 \\
& Interesse dos cidadãos & 0,07 & 4,53 & 0,69 \\
\hline
\end{tabular}

Fonte: Elaborada pelos autores (2020).

No que tange aos fatores políticos observou-se que Barra Funda, Lagoa dos Três Cantos, Nova Pádua, Protásio Alves e São José do Herval não tiveram competitividade política na última eleição, pois, apresentaram somente um candidato nas eleições para prefeito municipal no ano de 2016. Enquanto Minas do Leão apresentou o maior índice $(43,12 \%)$. A média da competitividade política dos municípios gaúchos na última eleição municipal (2016) foi de 12,72\%.

Santa Clara do Sul apresentou a maior participação eleitoral $(95,21 \%)$ e Cidreira a menor (57,62\%). A média de eleitores que participaram da última eleição foi de $83,40 \%$. O prefeito mais velho é do município de ljuí (75 anos) e o mais novo de Quevedos (27 anos). A idade média dos gestores municipais gaúchos é de 51,72 anos.

A média da transparência dos municípios foi de 7,71, sendo que os municípios mais transparentes são Maçambará, Nova Pádua, Porto Alegre, Venâncio Aires e Santa Cruz do Sul com nota 10. O município menos transparente é Maquiné com nota 1,4.

Sobre o interesse dos cidadãos, a média entre os municípios foi de 0,69 , sendo que o município que registrou o maior interesse foi São Lourenço do Sul $(4,53)$ e o menor interesse foi observado no município de Alvorada $(0,07)$.

Finalmente, na Tabela 2 são demonstradas as frequências das variáveis qualitativas e seus respectivos percentuais. 
Tabela 2 - Análise Descritiva das Variáveis Qualitativas

\begin{tabular}{|c|c|c|c|c|}
\hline Fatores & Variável & Resposta & Frequência & Percentual (\%) \\
\hline \multirow{6}{*}{ Políticos } & \multirow{2}{*}{ Reeleição } & Não & 51 & 85 \\
\hline & & Sim & 9 & 15 \\
\hline & \multirow{2}{*}{$\begin{array}{l}\text { Sexo do Gestor } \\
\text { Municipal }\end{array}$} & Masculino & 55 & 91,7 \\
\hline & & Feminino & 5 & 8,3 \\
\hline & \multirow{2}{*}{$\begin{array}{c}\text { Educação do Gestor } \\
\text { Municipal }\end{array}$} & $\begin{array}{l}\text { Possui Ensino } \\
\text { Superior }\end{array}$ & 28 & 46,7 \\
\hline & & $\begin{array}{l}\text { Não Possui Ensino } \\
\text { Superior }\end{array}$ & 32 & 53,3 \\
\hline
\end{tabular}

Fonte: Elaborada pelos autores (2020).

Observa-se que ocorreu reeleição em 51 (85\%) dos municípios e não ocorreu em 9 (15\%) dos municípios. Quanto ao sexo dos gestores municipais a maioria, $55(91,70 \%)$ são do sexo masculino e $5(8,30 \%)$ são do sexo feminino. Os gestores que possuem ensino superior são representados por $28(46,70 \%)$ e os que não possuem somam 32 (53,30\%).

\subsection{TESTES DE HIPÓTESES PARA AS VARIÁVEIS DO ESTUDO}

Em seguida será apresentado o teste de normalidade K-S para as variáveis do estudo (Tabela 3). Podese observar que as variáveis que apresentaram distribuição normal foram: atividade virtual, competitividade política, participação eleitoral e idade do gestor municipal.

Tabela 3 - Teste de normalidade K-S para as variáveis do estudo

\begin{tabular}{cc}
\hline Variável & Resultado do Teste (sig.) \\
\hline Atividade Virtual & 0,456 \\
Tamanho da população & 0,000 \\
Idade da população & 0,000 \\
Escolaridade da população & 0,000 \\
Capacidade econômica & 0,000 \\
Renda per capita & 0,002 \\
Competitividade política & 0,072 \\
Participação eleitoral & 0,158 \\
Idade do gestor municipal & 0,253 \\
Transparência & 0,036 \\
Interesse dos cidadãos & 0,001 \\
\hline
\end{tabular}

Fonte: Elaborada pelos autores (2020).

Na Tabela 4 podem ser observados os testes de hipóteses para dois grupos, considerando a variável atividade virtual. Para todas as variáveis foi realizado tanto o teste t para amostrar independentes quanto o teste de Mann-Whitney e ambos deram o mesmo resultado para todas as variáveis testadas. Portanto, todos os resultados vão ser analisados pelo teste t por ser um teste do tipo paramétrico. 
Tabela 4 - Teste de hipóteses para dois grupos, considerando como dependentes a variável atividade virtual

\begin{tabular}{|c|c|c|c|c|c|c|c|c|c|}
\hline \multirow{2}{*}{ Variável } & \multirow{2}{*}{ Grupo } & \multirow{2}{*}{$\begin{array}{c}\text { Média } \\
\text { Variável } \\
\text { Atividade } \\
\text { Virtual }\end{array}$} & \multicolumn{5}{|l|}{$\begin{array}{l}\text { Teste de } \\
\text { Levene }\end{array}$} & \multirow{2}{*}{$\begin{array}{c}\text { Teste de } \\
M-W\end{array}$} & \multirow[t]{2}{*}{$\begin{array}{l}\text { Condição da } \\
\text { hipótese* }^{*}\end{array}$} \\
\hline & & & $\mathbf{F}$ & Sig & Teste $\mathbf{t}$ & Df. & $\begin{array}{c}\text { Sig (2 } \\
\text { extremidades) }\end{array}$ & & \\
\hline Tamanho da população & $\begin{array}{l}\text { Menor População } \\
\text { Maior População }\end{array}$ & $\begin{array}{l}196,500 \\
314,333\end{array}$ & 0,402 & 0,528 & $-3,900$ & 58 & 0,000 & 0,001 & $\begin{array}{l}\text { Hipótese aceita } \\
(\mathrm{H} 1)\end{array}$ \\
\hline População Idosa & $\begin{array}{l}\text { Menos idosos } \\
\text { Mais idosos }\end{array}$ & $\begin{array}{l}186,633 \\
324,200\end{array}$ & 0,481 & 0,491 & $-4,786$ & 58 & 0,000 & 0,000 & $\begin{array}{l}\text { Hipótese aceita } \\
(\mathrm{H} 2)\end{array}$ \\
\hline $\begin{array}{l}\text { Escolaridade da } \\
\text { População }\end{array}$ & $\begin{array}{l}\text { Menos pessoas com ensino superior } \\
\text { Mais pessoas com ensino superior }\end{array}$ & $\begin{array}{l}185,000 \\
325,833\end{array}$ & 0,974 & 0,328 & $-4,947$ & 58 & 0,000 & 0,000 & $\begin{array}{l}\text { Hipótese aceita } \\
(\mathrm{H} 3)\end{array}$ \\
\hline Capacidade Econômica & $\begin{array}{l}\text { Menor receita arrecadada } \\
\text { Maior receita arrecadada }\end{array}$ & $\begin{array}{l}191,867 \\
318,967\end{array}$ & 1,018 & 0,317 & $-4,299$ & 58 & 0,000 & 0,000 & $\begin{array}{l}\text { Hipótese aceita } \\
(\mathrm{H} 4)\end{array}$ \\
\hline Renda & $\begin{array}{l}\text { Menor renda } \\
\text { Maior renda }\end{array}$ & $\begin{array}{l}241,355 \\
270,448 \\
\end{array}$ & 0,688 & 0,410 & $-0,862$ & 58 & 0,392 & 0,482 & $\begin{array}{c}\text { Hipótese } \\
\text { rejeitada }(\mathrm{H} 5) \\
\end{array}$ \\
\hline Competitividade Política & $\begin{array}{l}\text { Menos competitividade } \\
\text { Mais competitividade }\end{array}$ & $\begin{array}{l}228,933 \\
281,900\end{array}$ & 0,482 & 0,490 & $-1,594$ & 58 & 0,116 & 0,119 & $\begin{array}{c}\text { Hipótese } \\
\text { rejeitada }(\mathrm{H} 6)\end{array}$ \\
\hline Reeleição & $\begin{array}{l}\text { Não houve reeleição } \\
\text { Houve reeleição }\end{array}$ & $\begin{array}{l}253,353 \\
267,111\end{array}$ & 0,850 & 0,361 & $-0,290$ & 58 & 0,773 & 0,877 & $\begin{array}{c}\text { Hipótese } \\
\text { rejeitada }(\mathrm{H} 7)\end{array}$ \\
\hline Participação Eleitoral & $\begin{array}{l}\text { Menor participação } \\
\text { Maior participação }\end{array}$ & $\begin{array}{l}303,742 \\
203,759\end{array}$ & 0,430 & 0,515 & 3,192 & 58 & 0,002 & 0,004 & $\begin{array}{c}\text { Hipótese aceita } \\
(\mathrm{H} 8)\end{array}$ \\
\hline Sexo do Gestor Municipal & $\begin{array}{l}\text { Masculino } \\
\text { Feminino } \\
\end{array}$ & $\begin{array}{l}253,945 \\
271,600 \\
\end{array}$ & 0,875 & 0,354 & $-0,288$ & 58 & 0,775 & 0,876 & $\begin{array}{c}\text { Hipótese } \\
\text { rejeitada }(\mathrm{H} 9) \\
\end{array}$ \\
\hline $\begin{array}{c}\text { Idade do Gestor } \\
\text { Municipal }\end{array}$ & $\begin{array}{l}\text { Mais novo } \\
\text { Mais velho }\end{array}$ & $\begin{array}{l}253,389 \\
258,458\end{array}$ & 0,648 & 0,424 & $-0,146$ & 58 & 0,884 & 0,982 & $\begin{array}{c}\text { Hipótese } \\
\text { rejeitada }(\mathrm{H} 10) \\
\end{array}$ \\
\hline $\begin{array}{c}\text { Grau de Instrução do } \\
\text { Gestor Municipal }\end{array}$ & $\begin{array}{l}\text { Não possui ensino superior } \\
\text { Possui ensino superior }\end{array}$ & $\begin{array}{l}239,875 \\
273,179\end{array}$ & 0,285 & 0,596 & $-0,987$ & 58 & 0,328 & 0,310 & $\begin{array}{c}\text { Hipótese aceita } \\
(\mathrm{H} 11)\end{array}$ \\
\hline Transparência & $\begin{array}{l}\text { Menos transparência } \\
\text { Maior transparência }\end{array}$ & $\begin{array}{l}248,645 \\
262,655\end{array}$ & 1,225 & 0,273 & $-0,413$ & 58 & 0,681 & 0,631 & $\begin{array}{c}\text { Hipótese } \\
\text { rejeitada (H12) }\end{array}$ \\
\hline Interesse do Cidadão & $\begin{array}{l}\text { Menor interesse } \\
\text { Maior interesse }\end{array}$ & $\begin{array}{l}268,452 \\
241,483 \\
\end{array}$ & 0,814 & 0,371 & 0,798 & 58 & 0,428 & 0,455 & $\begin{array}{c}\text { Hipótese } \\
\text { rejeitada }(\mathrm{H} 13) \\
\end{array}$ \\
\hline
\end{tabular}


Conforme pode ser observado na Tabela 4, o teste t para amostras independentes, considerando os fatores demográficos, indica que há diferença estatisticamente significativa na variável tamanho da população $(\mathrm{t}(58)=-3,900, \mathrm{p}<0,05)$. Em média, os municípios com população maior $(\overline{\mathrm{X}}=314,333, \mathrm{~s}=114,6624)$ possuem mais atividade virtual do que os municípios de população menor ( $\bar{X}=196,500, s=119,3542)$. Ao nível de $5 \%$ de significância rejeita-se a hipótese nula e aceita-se a Hipótese 1 proposta nesta investigação. Em consonância, Bonsón, Royo e Ratkai (2016) indicam que as cidades maiores, que por serem mais visíveis ao público, usam o Facebook em maior medida. Guillamón et al. (2016) constataram, ao pesquisar 217 municípios italianos e espanhóis, que a divulgação de informações através de aplicativos de mídia social é superior quando o tamanho da população dos municípios é maior, corroborando com os resultados deste estudo.

A atividade virtual das prefeituras gaúchas é maior em municípios onde a concentração de pessoas com idade igual ou superior a 60 anos é maior $(\bar{X}=324,200, s=108,8851)$ do que nos municípios de menor número de pessoas idosas ( $\bar{X}=186,633, s=113,7106)$, em média. Rejeita-se a hipótese nula ao nível de $5 \%$ de significância $(\mathrm{t}(58)=-4,786, \mathrm{p}<0,05)$ e aceita-se a Hipótese 2 proposta nesta investigação. Uma pesquisa realizada por Wasserman et al. (2012) indica o Facebook como a rede social mais utilizada pelos idosos. $O$ Facebook se destaca pela simplicidade de postar e se comunicar com facilidade, "sendo uma maneira prática de manifestação dos usuários" (p. 6).

Em média, a atividade virtual nos grupos com maior e menor número de pessoas com ensino superior completo é diferente estatisticamente $(t(58)=-4,947, p<0,05)$. Rejeita-se a hipótese nula e se aceita a Hipótese 3 proposta nesta investigação. Ao nível de $5 \%$ de significância, conclui-se que, em média, a atividade virtual dos municípios que possuem uma concentração maior de pessoas com ensino superior $(\bar{X}=325,833$, $s=104,5371$ ) é maior do que os municípios onde a concentração de munícipes com formação superior é menor $(\bar{X}=185,000, s=115,7050)$.

Um estudo realizado por Marques, Aquino e Miola (2014), verificou que deputados eleitos por constituintes com maior nível de escolaridade possuíam maior atividade na rede social Twitter, corroborando com os resultados desta pesquisa. Em concordância, Faber, Budding e Gradus (2019) enfatizam que o uso de mídias sociais é caracterizado pela presença de pessoas com formação superior. Portanto, os municípios com moradores com nível mais alto de educação possuem atividade virtual maior.

Com relação aos fatores econômicos observou-se que existe diferença estatisticamente significativa entre a média da atividade virtual dos grupos de maior e menor capacidade econômica $(t(58)=-4,299, p<0,05)$. Conclui-se que, em média, a atividade virtual é maior em municípios com maior receita arrecadada ( $\bar{X}=318,967$, $s=108,6902)$ do que os municípios com menor receita arrecadada ( $\bar{X}=191,867, s=120,0223)$. Portanto, rejeitase a hipótese nula e aceita-se a Hipótese 4 proposta neste estudo. Ribeiro e Zuccolotto (2012) enfatizam que municípios com maior capacidade econômica têm disponível mais recursos para investir na gestão de informação, por isso tendem a divulgar mais conteúdos em meio eletrônico de acesso público. Vale destacar ainda que criar uma conta no Facebook é relativamente simples e possui custos muito baixos, mas realizar sua manutenção e monitoramento apropriados pode gerar vários custos em termos de tempo e recursos (LAMEIRAS; SILVA; TAVARES, 2018).

Para a variável renda, a atividade virtual, em média, é igual em municípios onde os trabalhadores formais recebem salários maiores $(\bar{X}=270,448, s=123,4830)$ do que nos municípios onde os salários são menores $(\bar{X}=241,355, s=136,9960)$. Aceita-se a hipótese nula ao nível de $5 \%$ de significância $(t(58)=-0,862$, p $>0,05)$ e rejeita-se a Hipótese 5 proposta nesta investigação. Esse resultado diverge do apresentado por Guillamón et al. (2016), já que os autores apontam que nos municípios italianos e espanhóis em que o nível de renda dos cidadãos é mais baixo, os governos locais são mais propensos a divulgar informações e oferecer serviços por meio de sites e/ou mídias sociais.

$O$ teste $t$ para amostras independentes também foi realizado para os fatores políticos. Em média, a atividade virtual é igual em municípios com maior competitividade política ( $\bar{X}=281,900, s=123,1695)$ e em municípios em que a competitividade é menor $(\bar{X}=228,933, s=133,9881)$. Aceita-se a hipótese nula (t $(58)=-$ $1,594, p>0,05)$ e rejeita-se a Hipótese 6 proposta nesta investigação. Ao nível de $5 \%$ de significância, concluise que não existe diferença estatisticamente significativa entre os dois grupos. Esse resultado desencontra-se 
com o de Lameiras, Silva e Tavares (2018), quando comparado à Portugal, que verificaram que os municípios estão mais ativos no Facebook onde as eleições são mais competitivas.

A atividade virtual é igual nos municípios gaúchos onde houve reeleição ( $\bar{X}=267,111, s=115,9843)$ e nos municípios em que não houve reeleição $(\bar{X}=253,353, s=133,6860)$, em média. Aceita-se a hipótese nula ao nível de $5 \%$ de significância $(t(58)=-0,290, p>0,05)$ e rejeita-se a Hipótese 7 proposta nesta investigação. Apesar de gestores públicos reeleitos estarem mais expostos nas mídias e, por isso, estarem mais ativos nas redes sociais (BRAMBOR; CENEVIVA, 2012), nesse estudo não se observou relação significativa entre a atividade virtual e condição de reeleição para os municípios investigados.

Em média, a atividade virtual é maior nos municípios com maior participação eleitoral ( $\bar{X}=203,759$, $s=124,3508)$ do que em municípios de menor participação ( $\bar{X}=303,742, s=118,3095)$. Essa diferença foi significativa $(t(58)=3,192, p<0,05)$. Portanto, rejeita-se a hipótese nula e aceita-se a Hipótese 8 proposta neste estudo.

Com relação ao perfil do gestor municipal os resultados expostos na Tabela 4 indicam que não existe diferença estatisticamente significativa para as três características analisadas (sexo, idade e grau de instrução).

Em média, a atividade virtual é igual nos municípios governados por mulheres $(\overline{\mathrm{X}}=271,600$, $s=122,2367)$ e em municípios em que o gestor é do sexo masculino ( $\bar{X}=253,945, s=132,0402)$. Aceita-se a hipótese nula ao nível de $5 \%$ de significância $(t(58)=-0,288, p>0,05)$ e rejeita-se a Hipótese 9 proposta nesta investigação. Um estudo anterior demonstrou que gestoras mulheres tendem a enfatizar a comunicação ao desempenhar suas funções e promover processos democráticos, considerando o cidadão uma parte importante do processo de tomada de decisão. As mulheres preferem estar inseridas em um contexto de interações do que estar no topo da hierarquia, valorizando as contribuições do cidadão (FOX; SCHUHMANN, 1999), sendo as redes sociais um ambiente propício para essa proximidade com os munícipes. Tavares e Cruz (2017) discorrem que os gestores do sexo masculino tendem a ser menos dispostos a aceitar a participação, direcionando-se a um estilo autoritário de liderança. Contudo, não foi encontrada diferença estatisticamente significativa para a atividade virtual de municípios governados por homens mulheres aqui investigados.

Não há diferença estatisticamente significativa para a variável idade do gestor $(t(58)=-0,146, p>0,05)$. Ao nível de $5 \%$ de significância conclui-se que, em média a atividade virtual dos municípios administrados por gestores mais novos $(\bar{X}=253,389, s=137,2827)$ é igual à dos municípios governados por prefeitos mais velhos $(\bar{X}=258,458, s=1220,595)$. Assim, rejeita-se a Hipótese 10 proposta neste estudo, indo de encontro aos resultados de Lameiras, Silva e Tavares (2018).

Em média, a atividade virtual é igual nos municípios em que o gestor possui ensino superior $(\bar{X}=273,179, s=137,3342$ ) e nos municípios onde o gestor não possui ensino superior $(\bar{X}=239,875, s=124,0270)$. Ao nível de $5 \%$ de significância aceita-se a hipótese nula $(t(58)=-0,987, p>0,05)$ e refuta-se a Hipótese 11 proposta nesta investigação. Este resultado contraria àquele indicado por Dreher et al. (2009).

Para a variável transparência, conforme pode ser observado na Tabela 4, não há diferença estatisticamente significativa para a atividade virtual entre os grupos com maior transparência e menor transparência $(\mathrm{t}(58)=-0,413, \mathrm{p}>0,05)$. Em média, a atividade virtual é igual em municípios mais transparentes $(\bar{X}=262,655, s=117,7480)$ e em municípios menos transparentes $(\bar{X}=248,645, s=142,7720)$. Com isso, aceita-se a hipótese nula e rejeita-se a Hipótese 12 proposta nesta investigação. Essa descoberta não corrobora com o que Haro-de-Rosario, Sáez-Martín e Caba-Pérez (2018) e Guillamón et al. (2016) apresentam em estudos realizados na Itália e Espanha. Para os autores, municípios com alto nível de uso do Facebook tendem a aumentar o grau de transparência, pois disponibilizam dados e informações sobre os serviços públicos que podem ser acessados facilmente pelos cidadãos. Na mesma linha de pensamento Bonsón et al. (2012) e Nica et al. (2014) ressaltam que usando plataformas de mídia social, o governo pode trazer agenda e atividades do setor mais próximas dos cidadãos, promover novas formas de prestação de contas e melhorar a transparência no setor público, vista como uma maneira de melhorar a confiança dos cidadãos nos governos.

Em média, a atividade virtual é igual em municípios onde o interesse do cidadão é maior $\overline{\mathrm{X}}=241,483$, $s=119,7851$ ) e em municípios em que o interesse do cidadão é menor ( $\bar{X}=268,452, s=140,2390)$. Aceita-se a hipótese nula ao nível de $5 \%$ de significância $(t(58)=-0,798, p>0,05)$ e rejeita-se a Hipótese 13 proposta nesta investigação. Vale destacar que essa variável de refere a proporção do número de fãs da página do Facebook 
de um município em relação ao tamanho da população. Lameiras, Silva e Tavares (2018) constataram que o interesse dos cidadãos nas contas do Facebook dos municípios portugueses incentiva a gestão pública a ser mais ativa na plataforma, sendo associado positivamente com a atividade virtual, divergindo com o resultado obtido neste estudo.

O teste t para amostras independentes demonstrou que as variáveis que correspondem aos fatores demográficos (tamanho da população, população idosa e escolaridade da população) são as mais significativas para a atividade virtual dos municípios gaúchos. Dos fatores econômicos apenas a capacidade econômica apresentou relevância e dos fatores políticos somente a participação eleitoral.

\section{CONSIDERAÇÕES FINAIS}

Nos últimos anos, o cidadão tem se mostrado mais engajado em assuntos governamentais, demonstrando interesse nas ações desenvolvidas pelos gestores públicos e percebendo uma maior necessidade de participação, o que fez com que os governos locais buscassem alternativas de aproximação com os munícipes.

A adoção das redes sociais pelas prefeituras possibilitou maior interatividade com os cidadãos, sendo que o Facebook é uma das plataformas mais utilizadas por essas instituições. Nesta perspectiva, este artigo objetivou comparar a atividade virtual média dos municípios gaúchos no Facebook considerando fatores demográficos, financeiros e políticos. O objetivo foi alcançado, sendo realizada coleta de dados em diversos sites e nas páginas do Facebook de 60 municípios do Rio Grande do Sul e a interpretação desses dados.

Foram atendidas sete, das 11 hipótese propostas nesta investigação $(\mathrm{H} 1, \mathrm{H} 2, \mathrm{H} 3, \mathrm{H} 4, \mathrm{H} 8, \mathrm{H} 9$ e H11), sendo que todas as hipóteses que abrangem fatores demográficos foram aceitas por meio do teste t. Quanto aos fatores econômicos, apenas uma hipótese foi atendida e refere-se à capacidade econômica. Para os fatores políticos, foram atendidas três, de um total de oito hipóteses propostas.

Em relação a análise descritiva constatou-se que a atividade virtual dos municípios se dá, em sua maioria, através de imagens e links, sendo que as publicações classificadas como vídeo, texto, gife status são pouco utilizadas pelos municípios gaúchos. No que concerne aos fatores demográficos observou-se que para as três variáveis (tamanho da população, população idosa e escolaridade da população), em média, existe diferença estatisticamente significativa para a atividade virtual dos municípios.

Com relação aos fatores econômicos, a capacidade econômica dos municípios afeta significativamente o nível de atividade virtual no Facebook e a renda per capita dos trabalhadores formais não apresentou significância. Assim conclui-se que a atividade virtual é diferente conforme a capacidade econômica dos municípios e igual no que tange à renda dos cidadãos.

Quanto os fatores políticos, contatou-se que para apenas uma das oito variáveis (participação eleitoral) a atividade virtual dos municípios gaúcho é diferente. Para as demais variáveis classificadas como políticas (competitividade política, reeleição, sexo do gestor municipal, idade do gestor municipal, grau de instrução do gestor municipal, transparência e interesse do cidadão) observou-se que a atividade virtual média dos grupos não é diferente. Conclui-se que a atividade virtual dos municípios é igual independente da competitividade nas eleições, do perfil do prefeito, da condição de reeleição, da transparência e do interesse do cidadão nas páginas dos municípios no Facebook.

Acredita-se que os resultados apresentados neste estudo podem ser aproveitados pelos prefeitos dos municípios gaúchos para aperfeiçoar sua atividade virtual no Facebook e outras redes sociais, promovendo uma maior interação com o cidadão, e este manifestar um maior interesse nas questões que envolvem a esfera pública. Os gestores municipais podem utilizar esses resultados para desenvolver novas práticas de publicações em suas redes sociais, capazes de divulgar atividades que abrangem o serviço público de uma maneira mais dinâmica e atrativa. Ressalta-se que a inserção das organizações públicas em ambientes virtuais pode promover a aproximação do governo com o cidadão, sobretudo com a criação de canais de comunicação e informação. 
Entende-se que uma das limitações deste estudo foi que para a composição da variável "interesse dos cidadãos", os dados coletados para a variável "tamanho da população" referem-se ao ano de 2016 e o "número de fãs" corresponde ao ano de 2019, podendo ter interferido em uma análise mais exata da variável.

Para pesquisas futuras sugere-se que a amostra seja ampliada para um contexto nacional, para verificar como se dá a atividade virtual dos municípios de diferentes estados do país e sua relação com fatores políticos.

Nota: Os dados coletados para este estudo podem ser acessados em:

https://docs.google.com/spreadsheets/d/1tkl8VT0QXpq73qZzl_GIZ908-WyrNt7r/edit\#gid=1787053808.

\section{Agradecimentos:}

Os autores agradecem ao CNPq - Conselho Nacional de Desenvolvimento Científico e Tecnológico - pelo apoio financeiro ao projeto de processo n 405563/2016-7.

\section{REFERÊNCIAS}

AGRESTI, Alan; FINLAY, Barbara. Métodos estatísticos para as ciências sociais. 4. ed. Porto Alegre: Penso, 2012.

ALBANO, Claudio Sonaglio; ARAUJO, Marcelo Henrique de; REINHARD, Nicolau. Fatores motivadores e facilitadores dos relacionamentos em redes: como os gestores públicos reconhecem esses fatores em dados governamentais abertos. Navus - Revista de Gestão e Tecnologia, Florianópolis, v. 7, n. 1, p. 73-92, jan./mar. 2017. DOI http://dx.doi.org/10.22279/navus.2017.v7n1.p73-92.462

AMARAL, Rogerio do. Exposição Privada nas Redes Sociais: uma análise sobre o Facebook na sociedade contemporânea. 2016a. 217f. Tese (Doutorado em Educação) - Faculdade de Ciências e Tecnologia, São Paulo, 2016.

ARAUJO, Beatriz Pozzobon. Redes sociais na Internet e novas formas de sociabilidade: um estudo do Facebook. In: CONGRESSO DE CIÊNCIAS DA COMUNICAÇÃO NA REGIÃO SUL. 13., maio/jun. 2012, Chapecó. Anais [...] Chapecó: Intercom, 2012. p. 1-13.

BONSÓN, Enrique et al. Local e-government 2.0: Social media and corporate transparency in municipalities. Governmente Information Quarterly, v. 29, n. 2, p. 123-132, abr. 2012. DOI https://doi.org/10.1016/j.giq.2011.10.001.

BONSÓN, Enrique; ROYO, Sonia, RATKAI, Melinda. Facebook Practices in Western European Municipalities: an empirical analysis of activity and citizens' engagement. Administration \& Society, v. 49, n. 3, p. 320-347, 2016. DOI https://doi.org/10.1177\%2F0095399714544945

BRAMBOR, Thomas; CENEVIVA, Ricardo. Reeleição e Continuísmo nos Municípios Brasileiros. Novos Estudos CEBRAP, São Paulo, n. 93, p. 9-21, jul. 2012. DOl https://doi.org/10.1590/S0101-33002012000200002.

BRASIL. Secretaria de Comunicação Social. Manual de orientação para atuação em mídias sociais: identidade padrão de comunicação digital do poder executivo federal. Versão 2.0. 2014. Disponível em: http://www.secom.gov.br/pdfs-da-area-de-orientacoes-gerais/internet-e-redessociais/secommanualredessociaisout2012_pdf.pdf>. Acesso em: 27 out. 2019.

CETIC - CENTRO REGIONAL DE ESTUDOS PARA O DESENVOLVIMENTO DA SOCIEDADE DA INFORMAÇÃO. Pesquisa Sobre o Uso das Tecnologias de Informação e Comunicação no Setor Público Brasileiro: TIC Governo Eletrônico 2017. São Paulo: Comitê Gestor da Internet no Brasil, 2017. 440 p. Disponível em: https://cetic.br/media/docs/publicacoes/2/TIC_eGOV_2017_livro_eletronico.pdf. Acesso em: 19 out. 2019.

CGU - CONTROLADORIA GERAL DA UNIÃO. Panorama dos Governos Estaduais, 2017. Disponível em: https://relatorios.cgu.gov.br/Visualizador.aspx?id_relatorio=22. Acesso em: 09 nov. 2019. 
DREHER, Axel et al. The impact of political leaders' profession and education on reforms. Journal of Comparative Economics, v. 37, p. 169-193, 2009.

DUGGAN, Maeve; BRENNER, Joanna. The Demographics of Social Media Users. Pew Research Center's Internet \& American Life Project, v. 14, p. 1-14, 2013.

EFFING, Robin; HILLEGERSBERG, Jos; HUIBERS, Theo. Social media and political participation: are Facebook, Twitter and YouTube democratizing our political systems? Electronic Participation (ePart), Delft, Netherlands, v.3, p. 25-35, ago. 2011. DOI 10.1007/978-3-642-23333-3_3.

FABER, Bram; BUDDING, Tjerk; GRADUS, Raymond. Keeping in touch with citizens online: social media usage in dutch local government. Documento de discussão do Tinbergen Institute, 2019. Disponível em: https://www.researchgate.net/publication/330528000_Keeping_in_Touch_With_Citizens_Online_Social _Media_Usage_in_Dutch_Local_Government. Acesso em: 24 out. 2019.

FACEBOOK. Alcance orgânico no Facebook: suas dúvidas respondidas. 2017. Disponível em: https://ptbr.facebook.com/business/news/BR-Alcance-organico-no-Facebook-suas-duvidas-respondidas. Acesso em: 27 nov. 2019.

FARRANHA, Ana Cláudia; SANTOS, Leonardo Tadeu dos. Administração pública, direito e redes sociais: o caso da CGU no Facebook. Revista Eletrônica do Curso de Direito da UFSM, Santa Maria, v. 10, n. 2, p. 742-767, 2015. DOI 10.5902/1981369419768.

FIELD, Andy. Descobrindo a estatística usando o SPSS. 2. ed. Porto Alegre: Artmed, 2009. E-book.

FOX, Richard L.; SCHUHMANN, Robert A. Gender and local government: a comparison of women and men city managers. Public Administration Review, v. 59, n. 3, p. 231-242, maio/jun. 1999. DOI 10.2307/3109951.

GIL, Antonio Carlos. Como elaborar projetos de pesquisa. 4. ed. São Paulo: Atlas, 2008.

GUILLAMÓN, María-Dolores et al. Factors influencing social media use in local governments: the case of Italy and Spain. Government Information Quarterly, v. 33, n. 3, p. 460-471, 2016. DOI https://doi.org/10.1016/j.giq.2016.06.005.

HARO-DE-ROSARIO, Arturo; SÁEZ-MARTÍN, Alejandro; CABA-PÉREZ, Maria del. Using social media to enhance citizen engagement with local government: Twitter or Facebook? New Media e Society, Espanha, v. 20, n. 1, p. 29-49, 2018. DOI https://doi.org/10.1177\%2F1461444816645652.

HOFMANN, Sara et al. What makes local governments' online communications successful? Insights from a multi-method analysis of Facebook. Government Information Quarterly, Amsterdam, v. 30, n. 4, p. 387-396, 2013. DOI https://doi.org/10.1016/j.giq.2013.05.013.

HOSSER, Carla et al. Portal da transparência: um estudo comparativo entre os municípios de porto alegre e pelotas. ConTexto, Porto Alegre, v. 15, n. 30, p. 94-110, maio/ago. 2015.

KLEINA, Nilton Cesar Monastier. O Facebook como repertório e esfera pública virtual nos protestos do "Não Vai Ter Copa". In: CONGRESSO BRASILEIRO DE CIÊNCIAS DA COMUNICAÇÃO, 36., set. 2014, Foz do Iguaçu. Anais [...] Foz do Iguaçu: Intercom, 2014.

LAMEIRAS, Mariana; SILVA, Tiago; TAVARES, António. An empirical analysis of social media usage by local governments in Portugal. In: INTERNATIONAL CONFERENCE ON THEORY AND PRACTICE OF ELECTRONIC GOVERNANCE, 11., 2018, Ireland. Anais [...] Ireland: ICEGOV'18, 2018.

LÓPEZ ALONSO, Esmeralda; MORENO LÓPEZ, Begoña. La gestión de los medios sociales en la Administración local: análisis de los municipios rurales españoles. Vivat Academia: Revista de Comunicación, Madrid, n. 148, p. 77-99, set./dez. 2019. DOI 10.15178/va.2019.148.77-99. 
LUCIANO, Edimara Mezzomo; WIEDENHÖFT, Guilherme Costa; SANTOS, Fábio Pinheiro dos. Promoting social participation through digital governance: identifying barriers in the Brazilian Public Administration. In: ANNUAL INTERNATIONAL CONFERENCE ON DIGITAL GOVERNMENT RESEARCH. 19., maio/jun. 2018, Delft. Anais [...] Delft, 2018.

LUPINACCI, Ludmila. Eu tenho tanto pra lhe falar, mas com palavras não sei dizer: Gif animado como recurso expressivo. In: CONGRESSO BRASILEIRO DE CIÊNCIAS DA COMUNICAÇÃO, 39., set. 2016, São Paulo. Anais [...] São Paulo: Intercom, 2016.

MARQUES, Francisco Paulo Jamil Almeida; AQUINO, Jakson Alves de; MIOLA, Edna. Parlamentares, representação política e redes socais digitais: perfis d uso do Twitter na Câmara dos Deputados. Opinião Pública, Campinas, v. 20, n. 2, p. 178-203, ago. 2014. DOI https://doi.org/10.1590/1807-01912014202178.

MARSHALL, Tara C.; LEFRINGHAUSEN, Katharina; FERECZI, Nelli. The Big Five, self-esteem, and narcissism as predictors of the topics people write about in Facebook status updates. Personality and Individual Differences, Elsevier, v. 85, p. 35-40, out. 2015. DOI https://doi.org/10.1016/j.paid.2015.04.039.

MERGEL, Ines. A framework for interpreting social media interactions in the public sector. Government Information Quarterly, Amsterdam, v. 30, n. 4, p. 327-334, 2013. DOI https://doi.org/10.1016/j.giq.2013.05.015.

NICA, Elvira et al. The effectiveness of social media implementation at local government levels. Transylvanian Review of Administrative Sciences, Edição Especial, p. 152-166, 2014.

PIRES, Atrícia Menezes. Transparência da Gestão pública: um estudo dos municípios de Santa Maria e Novo Hamburgo/RS. 2013. 50 f. Monografia (Especialista em Gestão Pública Municipal) - Universidade Federal de Santa Maria, Santa Maria, 2013.

REIS, Leiliane de Almeida. Comunicação governamental no Facebook: a página da Prefeitura de Curitiba e o humor nas publicações. 2015. 81 f. Monografia (Bacharelado em Comunicação Social com habilitação em Jornalismo) - Faculdade de Comunicação Social da Universidade Federal de Juiz de Fora, Juiz de Fora, 2015.

RIBEIRO, Clarice de Paiva; ZUCCOLOTTO, Robson. Fatores determinantes da transparência na gestão pública dos municípios brasileiros. In: ENCONTRO DE ADMINISTRAÇÃO PÚBLICA E GOVERNO, Salvador, nov. 2012. Anais [...] Salvador: ANPAD, 2012.

RODRÍGUEZ-DOMÍNGUEZ, Luis; SÁNCHEZ, María García; ÁLVAREZ, Isabel Gallego. From emerging to connected e-government: the effects of socioeconomics and internal administration characteristics. The International Journal of Digital Accounting Research, Salamanca, v. 11, p. 85 - 109, 2011. DOI 10.4192/1577-8517-v11_5.

ROENGTAM, Sataporn. Social Media Use and Citizen Engagement in Local Government of Thailand. Management of Cities and Regions, 2017.

ROSA, Amanda Regina; CRUZ, Felipe Sales; EMERIM, Cárlida. Estudos preliminares sobre Metodologias de Análise de Imagens em movimento no jornalismo. In: CONGRESSO DE CIÊNCIAS DA COMUNICAÇÃO DA REGIÃO SUL. 19., Cascavel, maio/jun. 2018. Anais [...] Cascavel: Intercom, 2018.

SANTANA, Marília Bareeto de; SOUZA Gabriela Boesing de Souza. Uso Das Redes Sociais Por Órgãos Públicos No Brasil E Possibilidades De Contribuição Do Monitoramento Para Gestão. Revista Gestão Organizacional, Chapecó, v. 15, Edição Especial, p. 99-107, 2017. DOI: http://dx.doi.org/10.21714/1679-18272017v15Ed.p99107

SANTOS, Gustavo Henrique Campos dos. $\mathbf{O}$ uso das mídias sociais no poder público: análise do perfil "Senado Federal" no Facebook. 2016. 146 p. Dissertação (Mestrado em Administração Pública) - Escola de Governo Professor Paulo Neves de Carvalho, Belo Horizonte, 2016. 
SANTOS, Valmaria Lemos da Costa; SANTOS, José Erimar. As redes sociais digitais e sua influência na sociedade e educação contemporâneas. Revista Holos, Rio Grande do Norte, v. 6, p. 307-328, 2014. DOI 10.15628/holos.2014.1936.

SONG, Changsoo; LEE, Jooho. Citizens' use of social media in government, perceived transparency, and trust in government. Public Performance \& Management Review, v. 39, n. 2, p. 430-453, 2016. DOI 10.1080/15309576.2015.1108798.

STATISTA. Facebook - Statistics \& Facts. 2019a. Disponível em: https://www.statista.com/topics/751/facebook/. Acesso em: 24 out. 2019.

STATISTA. Number of Facebook users in Brazil from 2017 to 2023 (in millions). 2019b. Disponível em: https://www.statista.com/statistics/244936/number-of-facebook-users-in-brazil/. Acesso em: 24 out. 2019.

TAVARES, Antonio F.; CRUZ, Nuno F. da. Explaining the transparency of local government websites through a political market framework. Government Information Quarterly, p. 1-13, 2017. DOI 10.1016/j.giq.2017.08.005.

URE, Mariano. La comunicación de la administración pública em las redes sociales: los casos de las ciudades de Buenos Aires y Bolonia. Revista Palabra Clave, v. 19, n. 1, p. 240-270, mar. 2016. DOI http://dx.doi.org/10.5294/pacla.2016.19.1.10.

VISENTINI, Monize Sâmara; SANTOS, Micheli dos. Transparência na Gestão Pública Municipal Evidenciada nos Portais Eletrônicos dos Municípios do Conselho Regional de Desenvolvimento (Corede) das Missões/RS. Desenvolvimento em Questão, ljuí, ano 17, n. 49, p. 158-175, out./dez. 2019. DOI https://doi.org/10.21527/2237-6453.2019.49.158-175.

WASSERMAN, Camila et al. Redes sociais: um novo mundo para os idosos. Novas Tecnologias na Educação CINTED-UFRGS, v. 10, n. 1, jul. 2012. DOI https://doi.org/10.22456/1679-1916.30863. 